\title{
Recent Applications of Magnesium Oxide (MgO) Nanoparticles in various domains
}

\author{
Manuel Fernandes, Kshitij RB Singh, Tanushri Sarkar, Pooja Singh, Ravindra Pratap Singh* \\ Department of Biotechnology, Faculty of Science, Indira Gandhi National Tribal University, Amarkantak 484886, Madhya Pradesh, \\ India
}

*Corresponding author: E-mail: rpsnpl69@gmail.com, ravindra.singh@igntu.ac.in; Tel.: (+91) 9109346565

DOI: $10.5185 /$ amlett.2020.081543

Magnesium oxide nanoparticles have emerged as a potential candidate for meeting ends of various problems due to its unique properties such as biodegradability, non-toxicity, inhibition of biofilm growth and degradation of harmful dyes such as methyl violet and many more. Along with its easy synthesis by methods such as sol-gel technique, precipitation method, and green synthesis, it is widely applicable for toxic waste remediation, antibacterial materials, removal of industrial pollutants and also used in antiarthritic and anti-cancer activities. Prior reviews have laid focus on singular domains whereas our review clubs three major domains i.e., clinical, agricultural and environmental that are involved in the day to day life of plants as well as animals. Besides the above information, properties, synthesis, nanotoxicity and future perspectives of magnesium oxide nanoparticles have also been elaborated in this review.

\section{Introduction}

Nanotechnology holds promises for numerous improvements and acts as a pillar for keeping researches of various fields ongoing. It is defined as the technology involved in synthesis, characterization, and to generate applications from the designed materials whose at least one dimension lies on nanometer scale [1]. Nanomaterials are structural components that ranges between 1-1000 nanometer and they are composed of subgroups with a size range of 1-100 nanometer particles, these particles are called as nanoparticles [2,3]. Nanoparticles are found in various shapes and structures such as conical, spiral, flat, hollow, etc. and they exhibit physical properties which are extraordinary than its bulk form and offers them unique mechanical strength, increased stability and several more. They are being widely used throughout which indicates that it possesses properties that are beneficial in multiple ways [4].

Magnesium oxide nanoparticles are grabbing more attention than various other metal oxide nanoparticles that are widely being used throughout various fields because they are promising structural materials in biological implants due to their high strength to weight ratio, low density, good functionality, recycling activity, nontoxic, and hygroscopic nature; these characteristics of magnesium oxide nanoparticles increases its utility manifolds and they also have various other properties such as high melting point, cost-effective production, biodegradability and biocompatibility. These magnesium oxide nanoparticles have wide range of applications in industries and biomedical for bone regeneration; as a medicine for anti-bactericidal and antimicrobial inhibition, they are also used in cryoinjury and apart from this they are also employed in sorption of uranium ions, catalysis, lithium ion batteries and toxic waste curation [2,5-9].
These nanoparticles are highly corrosive in nature, thus their use in the field of automotive and aerospace was inhibited, but techniques such as plating, conversion coating, etc. have brought the metal back in the race [10].

Metal oxide nanoparticles play a vital role in environmental remediation by treating waste water, industrial and domestic waste, soil sediments as well as atmospheric pollution [11]. Magnesium oxide nanoparticles possess numerous properties such as they act as anti-biofilm agents; they also exhibit self-cleaning activity which helps them degrade methyl violet dye as well as removal of phosphorus from wastewater which is a reason for inhibiting plant growth [12-14]. Magnesium hydroxide and magnesium oxide nanoparticles possess excellent luminescence for photonic applications, because of its unique thermal properties, biodegradability activity, and non-toxic nature. The purified form of magnesium oxide nanopowder is used to improve mechanical and fabrication characteristics of aluminum as an alloy; they are also used in manufacturing of missiles and dietary supplements because of their enormous properties such as light weight and edibility $[\mathbf{1 5}, \mathbf{1 6}]$.

Quasi-one-dimensional nanomaterials such as nanorods, nanotubes, and nanobelts are widely used for the production of chemo-resistive nanosensors [17]. Thus, synthesized magnesium oxide composites by thermal evaporation method can be used as good immobilization material for the development of hydrogen peroxide $\left(\mathrm{H}_{2} \mathrm{O}_{2}\right)$ biosensors based on horseradish peroxidase; many more different types of electrochemical and optical biosensors can also be made by utilizing these magnesium oxide composites $[\mathbf{1 8 , 1 9}]$.

\section{Properties}

Along with increasing applications of various metal oxide nanoparticles, magnesium oxide nanoparticles have also 


\section{Advanced Materials Letters www.vbripress.com/aml}

gained lot of attention and is being widely used because of the unmatchable properties it possesses. Magnesium oxide nanoparticles are easy to synthesize, nontoxic and inexpensive as well as are well known to own anti bactericidal (against Syaphylococcus aureus) and antimicrobial properties (against plant pathogenic bacteria) [20]. Magnesium oxide nanoparticles are generally found to be around 5-100nm in size and within a specific surface area of $25-50 \mathrm{~m}^{2} / \mathrm{g}$. Though these metal oxide nanoparticles are extremely small in size but possess melting point and boiling point of extremely high temperature, which is multifold its bulk material, i.e., $2852^{\circ} \mathrm{C}$ and $3600^{\circ} \mathrm{C}$ respectively. Magnesium oxide nanoparticles are in enormous use because of the novel properties it possesses such as simple stoichiometry, crystal structure, high ionic character and structural defects on the surface [21]. Magnesium oxide is known to possess a halite or cubic structure with an empirical formula of $\mathrm{MgO}$ and lattice arrangement of $\mathrm{Mg}^{2+}$ ions $\mathrm{O}^{2-}$ ions in ionic bonding [22]. As far as one of the major physical property of this metal oxide nanoparticles is concerned i.e., solubility in water it can be said that magnesium oxide nanoparticles are faintly soluble in water with a proportion of $0.0086 \mathrm{~g} / 100 \mathrm{ml}$ at a temperature of $20^{\circ} \mathrm{C}$. These nanoparticles and the products synthesized by it ought to be filled with properties such as dust repellent, wear resistant, fire resistant along with a high intensity, hardness and thermal insulation [23].

\section{Synthesis}

Synthesis, which is considered as the soul method for obtaining information about nanomaterials, is very important to be highlighted. There are many methods for the synthesis of nanoparticles which differs from nanomaterial to nanomaterial and different methods opted such as physical, chemical or green synthesis [24]. Due to the adverse effects of toxic elements present in chemical and physical ways of synthesis, eco-friendly method is an excellent alternative which can also be preferred [25]. This eco-friendly method of synthesis can either be green synthesis or biological method of synthesis [26]. Green synthesis is a method for the preparation of nanoparticles without the use of chemicals method, which includes microorganisms, enzymes, plants as well as plant extracts, thus it is also called as biosynthesis of nanoparticles [27]. This biosynthetic method generally includes microorganisms such as bacteria, fungi, algae, etc. and they are also being widely used in the synthesis of gold and silver nanoparticles [28]. Synthesis methods of nano-sized particles may cause technical and ecological problems and thus to avoid these an alternative technology should be used for the production of nanoparticles with minimal/ negligible toxic wastes and such a method is green synthesis of nanoparticles. Apart from green synthesis method there are several other which includes hydrothermal method, sol-gel technique, co-precipitation method and many more [29].

Table 1. Synthesis of Magnesium oxide nanoparticles by different methods.

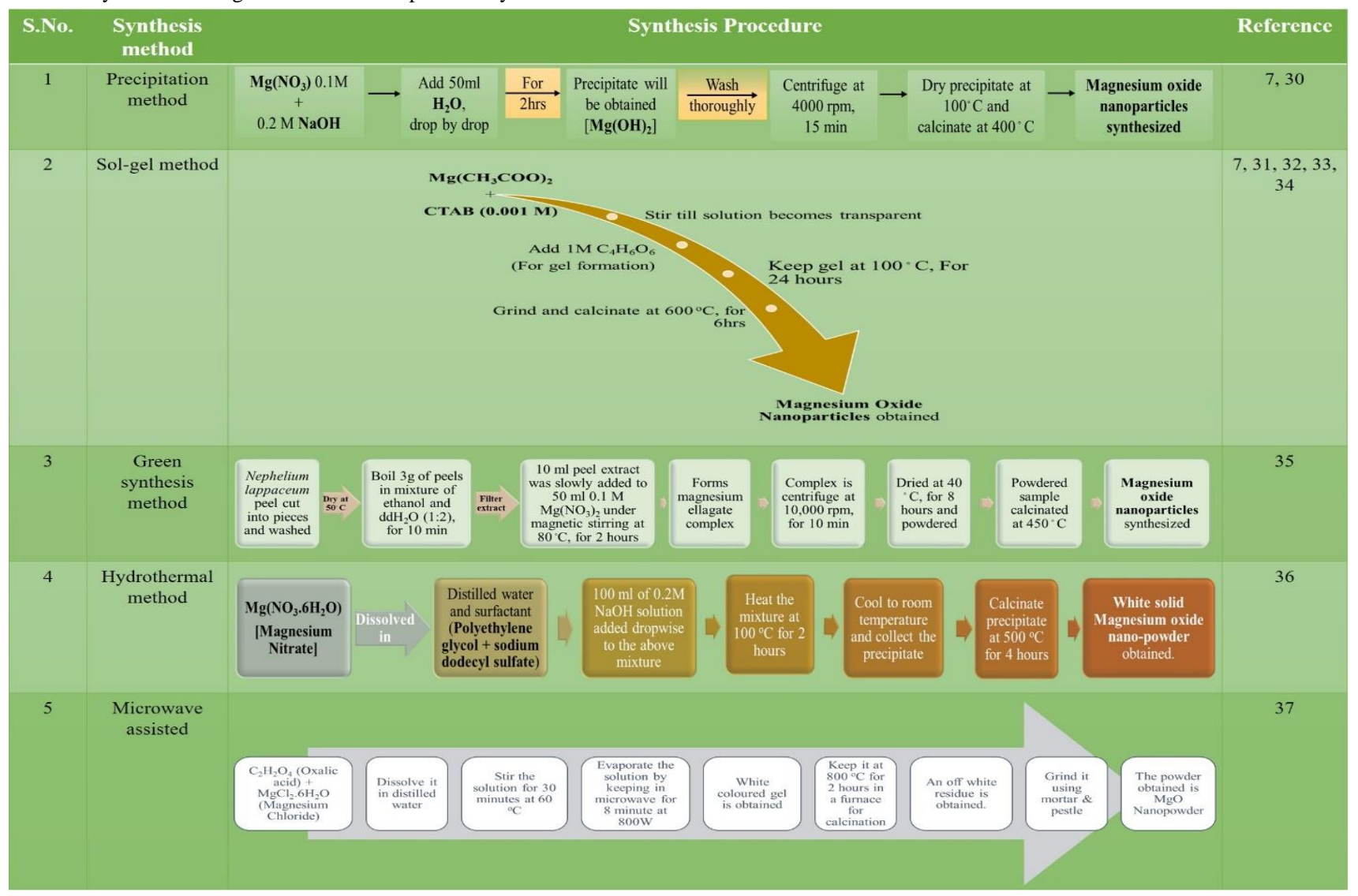




\section{Advanced Materials Letters www.vbripress.com/aml}

Herein, for the synthesis of magnesium oxide nanoparticles, a brief information about a few methods of synthesis highlighting sol-gel technique, hydrothermal method, precipitation method and microwave assisted synthesis of magnesium oxide nanoparticles are listed in Table 1 with complete protocol of synthesis [30-37]. These techniques are the most widely preferred methods because these methods are very fast and safe techniques including less time consumption and non-toxicity. The green synthesis method should be suggested to be used widely because it is the technique which does not involve the use of chemicals thus, making the it a safest technique of synthesis. Whereas, the microwave assisted technique is very commonly used now a days because it is faster, simpler and energy efficient technique in comparison to others. After the complete synthesis of nanoparticles, the detailed information about the size, shape, structure, crystallinity, etc., can be characterized by utilizing different sophisticated instruments such as transmission electron microscope, scanning electron microscope, XRay diffraction, dynamic light scattering, Fourier transfer infrared spectroscopy and UV-Vis spectroscopy $[\mathbf{3 8}, \mathbf{3 9}]$.

Through passing years researchers have synthesized magnesium oxide nanoparticle and studied them in detail for their properties and applications [40-46]. Many research groups have reviewed their properties, synthesis, and applications. Hence, in this review of magnesium oxide nanoparticles we have covered various methods of synthesis, properties, applications in the clinical, agricultural and environmental domains, along with nanotoxicity and its varied future aspects are discussed and elaborated.

\section{Applications}

\section{Agricultural}

Magnesium oxide nanoparticles have also been known to comprise a number of advantages such as negligible phytotoxicity, thermal stability, non-genotoxicity as well as non-biotoxicity to humans, enabling brilliant application prospects for plant protection [47]. These nanoparticles apart from the above-mentioned properties have various other characteristics too which offers them prominent application in the various other agricultural prospects as illustrated in Fig. 1 [48]. Further these nanoparticles also help in increasing agricultural production of peanut by enhancing the development of seedling and plant growth as well as are being used as an approved food additive, food supplement, color retentate, etc. $[49,50]$.

\section{Anti-microbial activity}

Magnesium oxide nanoparticles possess antibacterial activity against food borne pathogens such as E. coli and Salmonella entiritidis by causing leakage in their cell membrane ultimately leading to the death of these microorganisms [51]. Bacterial brown stripe is a disease known to spread among rice which completely destroys its
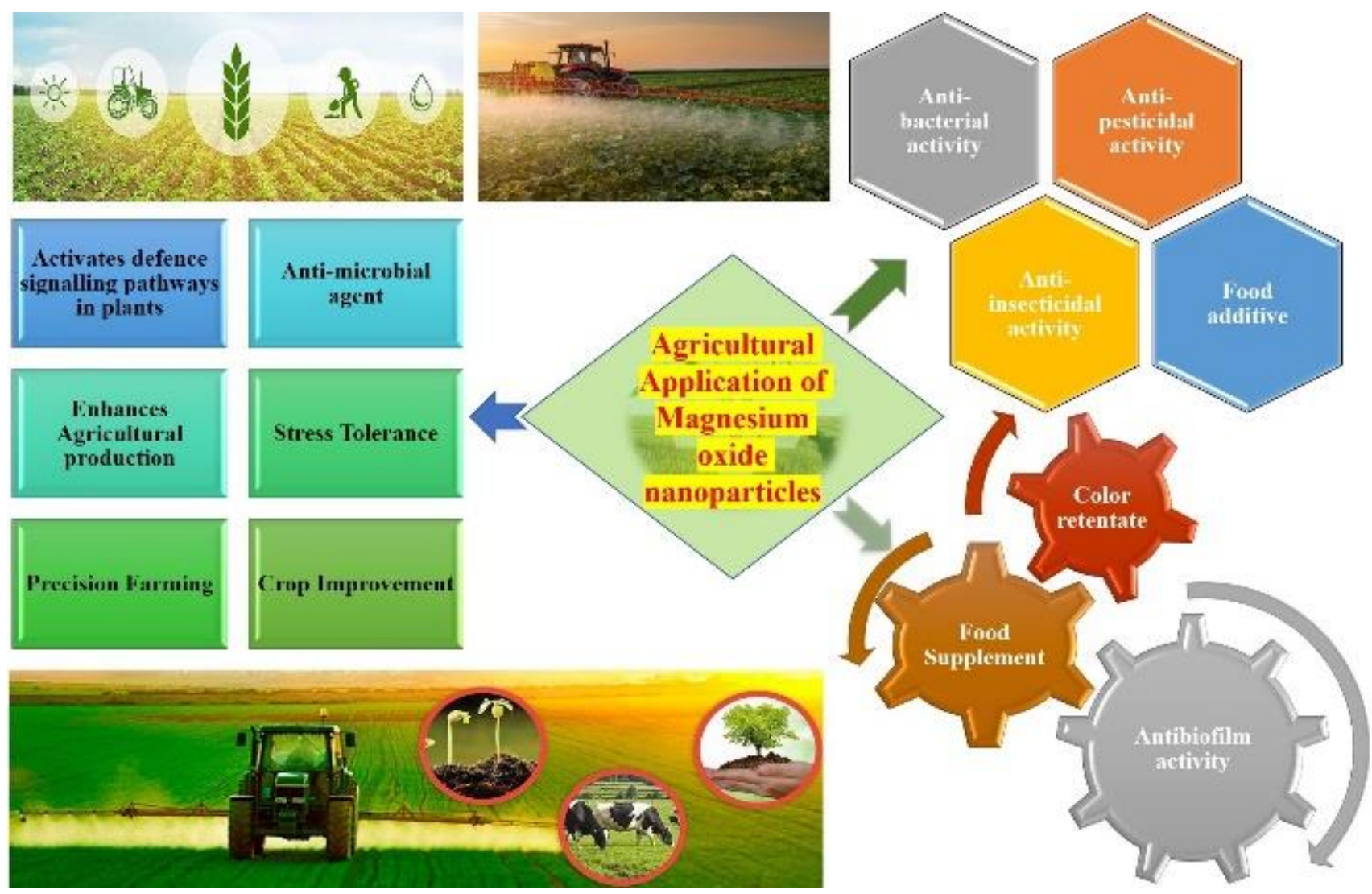

Fig. 1. Potential applications of Magnesium oxide nanoparticles in the agricultural domain. 


\section{Advanced Materials Letters www.vbripress.com/aml}

cultivation and is caused because of Acidovorax oryzae bacterial strain. Thus, in this regard S.O. Ogunyemi, $\mathrm{F}$ et al., reported the biosynthesis of magnesium oxide nanoparticles by using Matricaria chamomilla $L$. and the synthesized nanoparticles showed good inhibitory effect on the growth of Acidovorax oryzae bacteria [52]. From another study conducted by a research group reported magnesium oxide nanoparticles positive antibacterial response against phytopathogenic bacteria which is responsible for causing the deadliest wilt disease in the $R$. solanacearum [53]. According to Y. Abdallah et al. not only magnesium nanoparticles but magnesium oxide nanoflowers have been brought into existence because they own properties to suppress bacterial infections and prevent crops from damage [54]. Magnesium has been an essential mineral element for maintaining balanced nutrition in plants and also participates in various physiological functions such as plant protection and pathogenesis because of which these magnesium nanoparticles are known to show adorable antifungal activity even amongst minimum amount of fungicidal concentration [55-58].

\section{Anti-insecticidal and anti-biofilm activity}

Bacillus thuringiensis produces cry gene which acts as an insecticide against several insects such as nematodes, but this protein gets discharged into soil by water and insecticidal activity gets hampered. So, W. Rao et al. demonstrated magnesium-based nanoparticles as carrier of cry protein by adhesion to these nanoparticles and then transferred on the surface of cotton leaves. The result of this study showed enhanced mortality rate of insect's manifold. Thus, magnesium-based nanoparticles act as nanocarrier for the transfer of cry protein thereby enhancing its application as a bioinsecticides [59]. These metal oxide nanoparticles are known to induce systemic resistance towards gram negative, plant pathogenic bacterium, $R$. solanacearum by restricting the formation of biofilm and it can also initiate signaling pathways of phytohormones such as salicylic acid and jasmonic acid which play important role in the defense mechanism of plants.

Hence, it can be emphasized that magnesium oxide nanoparticles in agricultural field as an anti-microbial, anti-insecticidal, and antibiofilm agent is very effective $[60,61]$.

\section{Environmental}

Environmental contamination is a serious problem which is faced by developed as well as developing nations around the globe. There are many ways to deal environmental contamination but the drawback which lies are the side effects of those cleansing agents when they themselves start behaving as a contaminant. Nanoparticles have evolved as an excellent alternative for various other ways of environmental cleanliness. Magnesium oxide nanoparticles, within a short span of time, has been successful in showing its presence in various environmental applications (Fig. 2) by the diverse range of properties it exhibits. These metal oxide nanoparticles possess high absorbing properties along with large surface area and high response capacity because of which they are being used as a potential absorbent of toxic gases such as nitrogen dioxide and sulfur dioxide [62-66].

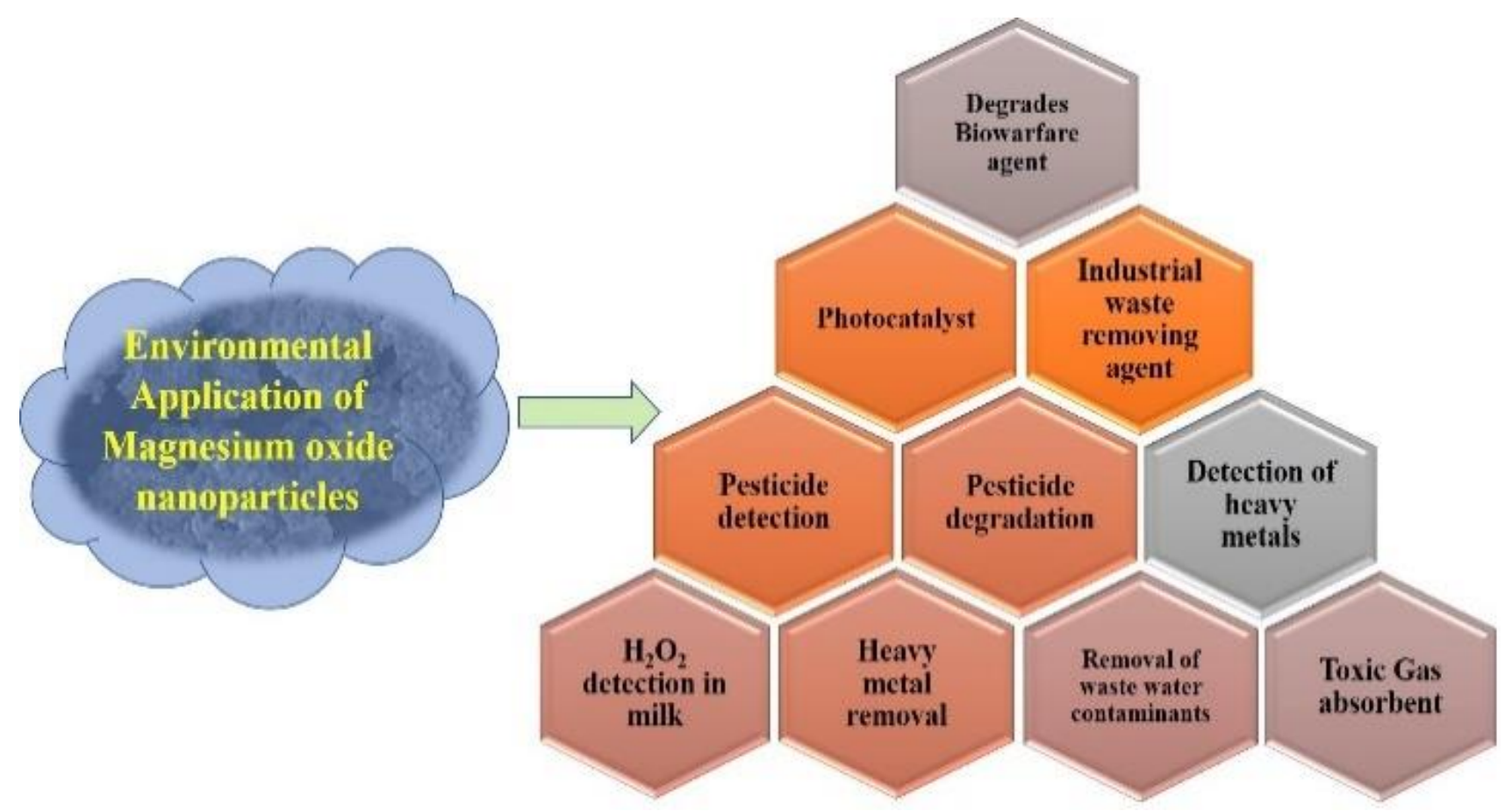

Fig. 2. Environmental applications of magnesium oxide nanoparticles. 


\section{Advanced Materials Letters www.vbripress.com/aml}

\section{Dye removal}

S. Jorfi et al., reported the removal of acid red 73dye which is a water contaminant released from textile industries in huge amount and B.J.H. $\mathrm{Ng}$ et al. demonstrated that magnesium oxide nanoparticle enhances the activity of ferrate VI which oxidize the Blue 203 dye (water contaminating dye from leather and cosmetic industries) $[67,68]$. Several other industries such as fabric and cloth industries also utilize ample of dyes for coloration of clothes and among them one of the most commonly used one is indigo carmine which is an effluent of water. A. Bagheri GH et al., synthesized magnesium oxide nanoparticles which acted as a photocatalyst for photocatalytic decolorization of indigo carmine [69]. 2,4Dichlorophenol (2,4-DCP) is a toxic compound commonly released from paper industries directly into different sources of water acting as a primary effluent in water. This chlorophenol compound $(2,4-\mathrm{DCP})$ has known to show adverse effects on the ones who consume it including plant, animals and humans but its treatment with magnesium oxide nanoparticles has led to its vigorous degradation because magnesium oxide acts as a catalyst in the degradation of this dye through ionization method [70].

\section{Heavy metal ion detection and removal}

The fritter from various industries and factories are drawn to different sources of water which contain toxic materials in the form of heavy metals. These heavy metals when enter plants, animals and humans shows negative effects in different ways. Y. Cai et al., demonstrated that magnesium oxide nanoparticles can be a novel candidate in the removal of heavy metals such as cadmium $\left(\mathrm{Cd}^{2+}\right)$ and lead $\left(\mathrm{Pb}^{2+}\right)$ [71]. Along with nanoparticles, nanocomposites such as magnesium oxide- copper oxide nanocomposites and magnesium oxide- manganese oxide nanocomposites are effective adsorbents and have shown high adsorbing property towards heavy metal ions such as lead, arsenic and mercury, making it a competitor of other nanoparticles involved in heavy metal removal from water [72]. G. Khayatian et al., brought forward the sensitivity of magnesium oxide nanoparticles by demonstrating that these nanoparticles when modifies with graphene oxide show remarkable detection of heavy metals such as copper, nickel and cadmium which are present in large amount in tap water, well water as well as sea water [73].

\section{Detection and removal and of chemical toxins}

The property of magnesium oxide nanoparticle as a detoxification agent is widely being used in various applications among which one is in detection and removal of chemical toxins. Bis(2-chloroethyl) sulphide which is commonly known as Sulphur mustard (a highly toxic chemical) which is generally used as biological warfare agent, can be degraded into non harmful products such as divinyl sulfide, 2-chloroethyl vinyl sulfide and thiodiglycol which are products of elimination and nuclephilic substitution reaction, respectively, when treated with magnesium oxide nanoparticles [74]. S. Ali et $a l$., stated that magnesium oxide nanoparticles and zincmagnesium oxide nanoparticles show degradation of a highly toxic contaminant, 2,4,6-trinitrophenyl, which is known to cause tumor, liver malfunctioning, skin related disorders, etc. [75].

\section{Pesticide degradation and hydrogen peroxide biosensor}

Though pesticides help in increasing yield of crops by keeping pests and insects away from damaging them but when these chemicals are drained out of field into different sources of water, cause various harmful diseases to plants and humans in many ways. L.E. Lange et al., reported that the etching of magnesium oxide nanoparticles blended with polypropylene enhances the chemical stability reactive sites present in the nanoparticles which degrades methyl parathion, an organophosphate pesticide [76]. The effect of diazinon pesticide, which has been banned by the Environmental Protection Agency due to its high toxic effects towards plants and humans, has found to be degraded when treated with aluminum oxide and magnesium oxide nanoparticles [77].

Hydrogen peroxide, which is a byproduct of high selective oxidative reactions, possesses major applications in various fields such as pharmaceutical, clinical, environmental, industrial, agricultural and many more. Thus, its detection via a sensitive and accurate method is necessary [78-80]. Biosensor devices are developed for the detection of hydrogen peroxide by the use of magnesium oxide nanoparticles as an inorganic material and chitosan as an organic polymer [81]. By utilizing magnesium oxide nanoparticles, nanosensors are also developed for the detection of hydrogen peroxide from milk. The nanobiosensor developed is highly sensitive and detects even a minute level of $\mathrm{H}_{2} \mathrm{O}_{2}$ presence and is also a cheap and rapid method of detection [82].

Despite the above mentioned applications of magnesium oxide nanoparticles there still lie several more such as very minute amount of these nanoparticles are enough for improving corrosion retardation ability of polyurethane films and these nanoparticles in addition with nanofiltration membrane are capable of removing pollutants such as organic matter, nitrogen species, heavy metals, bacteria and suspended solid particles and make it suitable for drinking $[\mathbf{1 4}, \mathbf{8 3}, \mathbf{8 4}]$. These nanoparticles have found a prominent place in waste water treatment because of the characteristics they possess such as high recovery and reproducibility, abrasiveness, electrostatic attraction, and oxidizing power combine to promote biocidal properties $[\mathbf{8 5}, \mathbf{8 6}]$.

\section{Clinical}

Among all properties and applications owned by magnesium oxide nanoparticles clinical aspects rule the chart because extravagant use of this metal oxide 


\section{Advanced Materials Letters www.vbripress.com/aml}

nanoparticle has been done in clinical field (Fig. 3). From curing diseases to find an alternative for uncurable ones and from disease diagnosis to plant and micro-organisms related issues, magnesium oxide nanoparticles have been successfully paved its way in the clinical domain [87].

APPLICATION OF MAGNESIUM OXIDE NANOPARTICLES IN CLINICAL

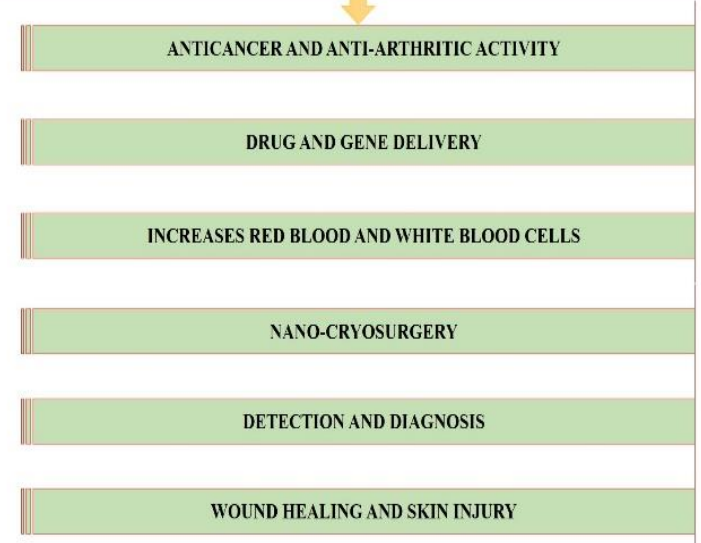

Fig. 3. Schematic presentation of vast application in the clinical domain of magnesium oxide nanoparticles.

\section{Therapeutics based on magnesium oxide nanoparticles}

As brought forth by two different group of researchers A. Mahmoud et al., and R. Goyal et al., magnesium oxide nanoparticles are known to acquire good anti-arthritic and anti-cancer activity and magnesium oxide with Iron particles are useful in magnetic resonance imaging, drug delivery, cancer therapy as well as cell sorting and also used as targeting agent in cryoinjury $[\mathbf{7 , 8 8 - 9 0}]$. Researches have suggested that magnesium oxide nanoparticles possess excellent antibacterial activity though this mechanism depends on the binding of nanoparticles to the surface of the bacteria [91,92]. They have known to show an increase in antibacterial activity against gram positive bacteria in comparison to gram negative because the latter holds a complex outer membrane which serves as an outstanding barrier against external materials but still magnesium nanoparticles have got hold of gram negative bacteria such as E coli and Staphylococcus aureus and showed antibacterial activity against them preventing cell death of many cells by reducing oxidative stress, lipid peroxidation as well as cell membrane damage $[\mathbf{5 , 3 2 , 9 3 -}$ 95]. Problems such as foot and mouth disease in cattle's, foodborne pathogens, treatment of the cotton fabric, the quality of bone cement used in fractures, medicine for bone regeneration and abdominal pain comprise of a common solution i.e., magnesium oxide nanoparticles [5, 96-98].

Mazaheri et al., on a specific note, stated that minute concentration as such below a range of $250 \mathrm{\mu gml}^{-1}$ these nanoparticles are known to be effective as they successfully increase red blood cells, white blood cells, hemoglobin, alkaline phosphatase, aspartate aminotransferase and simultaneously enhance bile duct proliferation and inflammation in areas of liver in rats and concurrently in the same minimal concentration itself these nanoparticles are considered safe according to in vivo toxicity investigations thus opening a way for these nanoparticles in drug encapsulation, disinfectant for edible substances [2,99-102]. Metal oxide nanoparticles are quite new in the field of research and thus being tried to be applied in almost every possible domain and thus in clinical as well because they are a replacement to many expensive and harmful methods that are being used in these domains at present. Through continuous research in clinical domain on magnesium nanoparticles, positive results come forth such as these nanoparticles provide precise drug delivery, improvement in permeability and unique targeting to tumors with minimal or no side effects. These nanoparticles as drug possess characteristics such as molecular weight, $\mathrm{pH}$, ionic strength, particle size, etc. and thus concurrently are also being used in nano-cryosurgery, hyperthermia, tumor inhibition and also in imaging of brain tumors [7,103-107].

With the increase in number of antibiotic resistant microbes the importance to create novel drugs have also increased rapidly and to overcome this problematic situation, scientists have turned their hopes on nanoparticles because of their cheap and easy availability, synthesis and possession of various applications in clinical domains. Fortunately, abundant nanoparticles can be used to fulfill the needful among which magnesium oxide nanoparticles remains comprised. Magnesium oxide nanoparticles can be used as an alternative for various traditional antibiotics because of its antibacterial properties [108]. E.R. Essien et al., reported the preparation of magnesium oxide nanoparticles by using aqueous extract of Manihot esculenta via green synthesis method but in general for the quick synthesis of these nanoparticles chemical methods are opted. The synthesized magnesium oxide nanoparticles prepared via green synthesis method possessed applications in catalysis and as an anti-microbial agent. This method was brought into sight to increase the synthesis of magnesium oxide nanoparticles via green synthesis method to not only reduce the use of chemicals but also because of its costefficient nature [43]. With loads of applications mentioned above, this metal oxide nanoparticle still possesses many more in this domain as magnesium nanoparticles are used in wound healing because of its ability to aid fibroblast adhesion after skin injury and as far as skin injury is concerned magnesium oxide nanoparticles should be synthesized in ethyl alcohol because they withhold excellent biocompatibility and antibacterial property $[\mathbf{1 0 9}$, 110]. The information provided by S. Hayat et al., depicts that magnesium oxide nanoparticles are effective and reliable antibiofilm agents that can inhibit adhesion, biofilm formation and remove the preformed biofilms of multidrug-resistant bacteria [111].

Electrospinning of magnesium oxide nanoparticles at a fixed concentration produces a complex composite nanofibrous scaffold which exhibits enhanced mechanical stability. Alginates, which are derivatives of 


\section{Advanced Materials Letters www.vbripress.com/aml}

Phaeophyceae (brown algae) when crosslinked with magnesium oxide to form magnesium-alginate scaffolds, yielded high tensile strength and enhanced thermal and mechanical stability. These magnesium-alginate scaffolds can be used as a substitute for extracellular matrix as a function for repairing and regeneration of tissues as these alternatives are affordable and adaptable [112]. Streptococcus mutans and Streptococcus sobrinus are two most commonly found bacteria in the oral cavity of humans and have been classified as carcinogenic microorganisms. Magnesium oxide nanoparticles along with glass-ionomer cement, which is a commonly used filling material in dentistry, are used as an antibacterial and antibiofilm agent to inhibit the growth and removal of these carcinogenic microorganisms. This biocompatible assortment of magnesium oxide nanoparticles and glassionomer cement can be a helpful tool for dentistry in near future [113]. Magnesium oxide nanoparticles pose a unique combination of properties such as biocompatibility, biodegradability, fluorescence which provides the ability to visualize cells and tissues and unlock ways for bioimaging applications, cutting-edge fluorescence guided surgery. These nanoparticles utilize enhanced permeability and retention (EPR) which binds to receptor binding ligands that are present on the surface of tumor cells. Magnesium nanoparticles act as a carrier of chemotherapeutic drugs to deliver them to the targeted tumor cell for improvement and minimization of toxicity [114].

\section{Diagnosis utilizing magnesium oxide based biosensors}

Magnesium oxide nanostructure have evolved recently which offer them unique surface immobilization, enhanced confirmation and stable biological activity of biomolecules which makes biosensors more sensitive [115]. These nanostructure metal oxides have unique properties such as optical, electrical, etc. which make them best candidate for utilization in biosensors [116]. Higher prevalence of lifestyle related disorder such as diabetes, cancer, hypertension, etc. [117] have demanded for better diagnostic systems which can be overcome by developing biosensor devices for the early and on-site detection of these deadly diseases. There are many pre-existing biosensors for these purposes based on different materials $[118,119]$, but magnesium oxide-based biosensors are currently revolutionizing these sensor technologies. Magnesium oxide nanoparticles along with its composites can be used for the detection of Vibrio cholerae via biosensors manufactured for the detection of DNA [120]. Z.Q. Lei et al. demonstrate that for biosensing of liver cancer the blend of magnesium oxide based magnetic tunnel junction and magnetic nanoparticles have shown reliable results [121]. M. Li et al. stated that magnesium oxide nanobelts-modified electrode shows high adsorption ability towards ascorbic acid, dopamine and uric acid [122]. A. Umar et al., reported highly sensitive glucose biosensor based on magnesium oxide nanocages and nanocrystals of polyhedral shape and their result showed high sensitivity and reproducibility [123].

\section{Nanotoxicity}

The varied range of Magnesium oxide nanoparticles has held it strong to accomplish applications in industries for cosmetics and skin care products as well as in biomedical for nanoelectronic biosensors, disease staging, etc. leaving behind some unwanted side effects, which are better pronounced as nanotoxicity. With a wide range of applications, comes along some negative effects of this metal oxide nanoparticle, about which much information is not yet gathered till date [109]. Nanoparticles, due to their small size and high reactivity can enter edible materials through their improper disposal into soil and water which can lead to adverse health effects. In couple of cases toxicity of magnesium oxide nanoparticles have been proven where V.B. Shah et al. reported the adverse effects of magnesium oxide nanoparticles leading to cellular apoptosis on the embryos of zebrafish $[\mathbf{1 1 0 , 1 2 4}]$ and it's also emphasized that magnesium oxide nanoparticles, in significant amount, when injected in Wistar rats resulted in alteration of biochemical pathways and DNA damage. Solely, not only magnesium oxide nanoparticles but $\mathrm{TiO} 2$ and cerium oxide nanoparticles along several others in the queue have been reported to cause toxicity in either plants or animals [112]. Although the toxicological effects of magnesium nanoparticles have been reported, but they are still widely used in various domains because the adverse effects of these nanoparticles are not proven to be lethal till date $[\mathbf{1 0 9 , 1 2 4 ]}$.

\section{Conclusion and prospects}

Magnesium oxide nanoparticles are widely being used in various domains such as automotive, aircraft, agriculture, environmental and biomedical, etc., and its use is spreading to almost every field due to its unique properties. Magnesium oxide nanoparticles synthesis through various method such as sol-gel, co-precipitation, hydrothermal, green synthesis, etc. are explained with complete procedure. Though nanotoxicity has evolved as a barrier in the way of these nanoparticles, they have paved a way out and are still being used vastly because of their various applications and properties.

Nanoparticles are showing promising application since near past and are to capture almost every field in near future because of their unbeatable properties. Magnesium has also gained attention by the synthesis of magnesium oxide nanoflowers, which are synthesized by using Rosemary extract; this can be widely used in agricultural fields to suppress bacterial infection [54] and through magnesia nanosheet arrays that are commonly found on the surface of magnesium alloys which can be useful in reinforcing composite materials or in further modification of other nanostructures. By combining the biodegradability and non-toxicity of magnesium oxide nanoparticles with their relatively lightweight and 


\section{Advanced Materials Letters www.vbripress.com/aml}

excellent thermal properties would help develop highperformance cryosurgery. Nanostructured metal oxides such as magnesium oxides can be utilized for developing sensitive biosensor devices by tailoring their properties. These nanostructured magnesium oxide tailored nanoparticles are the next generation of smart miniaturized biosensing devices $[\mathbf{1 1 6 , 1 2 5}]$. The study conducted by a group of researchers demonstrated for the first time, use of magnesium oxide nanoparticles for glucose biosensor fabrication [123].

Hence, these nanoparticles can be utilized in all the fields due to its enormous properties and to ensure complete safety before being completely commercialized, evaluation of these nanoparticles is on full swing because commercialization of this metal oxide nanoparticle will introduce an era of ecofriendly and cost-effective applications. Thus, nanostructured magnesium oxides have potential as an electron mediator for the fabrication of more sensitive biosensors for environmental pollution detection, biomedical diagnosis, etc. [126]. This review elaborates the synthesis, nanotoxicty, and current utility of magnesium oxide nanoparticles in agricultural, environmental, and clinical fields. There is very less reports related with utilization of magnesium oxide nanoparticles in the field of agriculture and environmental, the need to explore the application of these nanostructures by the researchers for their mode of mechanism data for plant growth, stress tolerance, and many more are still needed to be carried out.

\section{Acknowledgements}

The authors would like to extend their gratitude of thanks to Vicechancellor, Indira Gandhi National Tribal University, for providing facilities to prepare this review and we are also thankful to all faculty members of Department of Biotechnology, Indira Gandhi National Tribal University, Amarkantak, M.P., India for their support.

\section{Competing interests}

The authors declare that they have no conflict of interest.

\section{Keywords}

Magnesium Oxide (MgO) nanoparticles, clinical, agriculture, environmental, nanotoxicity, biosensors.

Received: 20 March 2020

Revised: 21 April 2020

Accepted: 27 April 2020

\section{References}

1. Silva, G.A.; Surg. Neurol., 2004, 61, 216.

2. Yang, W.; Peters, J.I.; Williams, R.O.; Int. J. Pharm., 2008, 356, 239.

3. Buzea, C.; Pacheco, I.I.; Robbie, K.; Biointerphases, 2007, 2.

4. Imani, M.M.; Safaei, M.; J. Nanotechnol, 2019.

5. Tang, Z. X.; Lv, B. F.; Brazilian J. Chem. Eng., 2014, 31, 591.

6. Sirota, V.; Selemenev, V.; Kovaleva, M.; Pavlenko, I.; Mamunin, K.; Dokalov, V.; Prozorova, M.; Phys. Res. Int., 2016, 1.

7. Krishnamoorthy, K.; Moon, J.Y.; Hyun, H.B.; Cho, S.K.; Kim, S. J.; J. Mater. Chem., 2012, 22, 24610.

8. Anu Mary Ealia, S.; Saravanakumar, M.P.; IOP Conf. Ser. Mater. Sci. Eng., 2017, 263, 032019.

9. Haldorai, Y., Shim, J. J.; Appl. Surf. Sci., 2014, 292, 447.

10. Gnedenkov, A.S.; Sinebryukhov, S.L.; Mashtalyar, D.V.; Gnedenkov, S.V.; Corros. Sci., 2016, 102, 269.
11. Khin, M.M.; Nair, A.S.; Babu, V.J.; Murugan, R.; Ramakrishna, S.; Energy Environ. Sci.; 2012, 5, 8075.

12. Chimenos, J.; Fernández, A.; Villalba, G.; Segarra, M.; Urruticoechea, A.; Artaza, B.; Espiell, F.; Water Res., 2003, 37, 1601.

13. Hikku, G.S.; J. K., Vignesh Kumar, S.; J. Ind. Eng. Chem., 2017, $52,168$.

14. Mahdavi, S.; Jalali, M.; Afkhami, A.; Chem. Eng. Commun., 2013, 200, 448.

15. Ramanujam, K.; Sundrarajan, M.; J. Photochem. Photobiol. B: Biol., 2014, 141, 296.

16. Anilkumar, M.R.; Nagaswarupa, H.P.; Nagabhushana, H.; Sharma, S.C.; Vidya, Y.S.; Anantharaju, K.S.; Prashantha, S.C.; Shivakuamra, C.; Gurushantha, K.; Spectrochim. Acta Part A Mol. Biomol. Spectrosc., 2015, 149, 703.

17. Wang, J.-S.; Feng, X.-Q.; Xu, J.; Qin, Q.-H.; Yu, S.-W.; J. Comput. Theor. Nanosci., 2011, 8, 1278.

18. Zhao, J.; Mu, F.; Qin, L.; Jia, X.; Yang, C.; Mater. Chem. Phys., 2015, 166, 176.

19. Ahammad, A.J.S.; J. Biosens. Bioelectron., 2012, s9.

20. Cai, L.; Chen, J.; Liu, Z.; Wang, H.; Yang, H.; Ding, W.; Front. Microbiol., 2018,

21. Bindhu, M.R.; Umadevi, M.; Kavin Micheal, M.; Arasu, M.V.; Abdullah Al-Dhabi, N.; Mater. Lett., 2016, 166, 19.

22. Taurian, O.E.; Springborg, M.; Christensen, N.E.; Solid State Commun., 1985, 55, 351.

23. Air Hardening Binding Materials, in: Build. Mater. Civ. Eng., Elsevier, 2011, pp. 29-423.

24. Singh, R.P.; Potential of Biogenic Plant-Mediated Copper and Copper Oxide Nanostructured Nanoparticles and Their Utility, in: Plant Nanobionics, Springer, Cham, 2019, pp. 115-176.

25. Singh, R.P.; Potential of Biogenic Plant-Mediated Iron and Iron Oxide Nanoparticles and Their Utility, in: Plant Nanobionics, Springer, Cham, 2019, pp.77-113.

26. Singh, R. P.; Shukla, V. K.; Yadav, R. S.; Sharma, P. K.; Singh, P. K.; Pandey, A. C.; Adv. Mater. Lett., 2011, 2, 313.

27. Shukla, V.K.; Singh, R.P.; Pandey, A.C.; J. Alloys Compd., 2010, 507, L13.

28. Hasan, S.; J. Recent. Sci., 2014, 4, 1.

29. Umaralikhan, L., Jamal Mohamed Jaffar, M.; Iran. J. Sci. Technol. Trans. A Sci., 2018, 42, 477.

30. Fedorov, P.P.; Tkachenko, E.A.; Kuznetsov, S. V.; Voronov, V. V.; Lavrishchev, S. V.; Inorg. Mater., 2007, 43, 502.

31. Mastuli, M.S.; Ansari, N.S.; Nawawi, M.A.; Mahat, A.M.; APCBEE Procedia, 2012, 3, 93.

32. Leung, Y.H.; Ng, A.M.C.; Xu, X.; Shen, Z.; Gethings, L.A.; Wong, M.T.; Chan, C.M.N.; Guo, M.Y.; Ng, Y.H.; Djurišić, A.B.; Lee, P.K.H.; Chan, W.K.; Yu, L.H.; Phillips, D.L.; Ma, A.P.Y.; Leung, F.C.C.; Small, 2014, 10, 1171.

33. Esmaeili, E.; Khodadadi, A.; Mortazavi, Y.; J. Eur. Ceram. Soc., 2009, 29, 1061.

34. Subramania, A.; Kumar, G.V.; Priya, A.R.S.; Vasudevan, T.; Nanotechnology, 2007, 18, 225601.

35. Suresh, J.; Yuvakkumar, R.; Sundrarajan, M.; Hong, S.I.; Adv. Mater. Res., 2014, 952, 141.

36. Duong, T.H.Y.; Nguyen, T.N.; Oanh, H.T.; Dang Thi, T.A.; Giang, L.N.T., Phuong, H.T.; Anh, N.T.; Nguyen, B.M.; Tran Quang, V.; Le, G.T.; Van Nguyen, T.; J. Chem., 2019, 2019, 1.

37. Maurya, A.; Bhatia, N.; Int. J. Eng. Res. Dev., 2017, 13, 1.

38. Singh, R.P.; Kumar, K.; Rai, R.; Tiwari, A.; Choi, J.W.; Pandey, A. C.; Synthesis, characterization of Metal oxide-based nanomaterials and its application in Biosensing, Nova Science Publishers, Inc. USA, 2012. Chapter 11, pp.225-238. In book "Synthesis, characterization and application of Smart material". Ed. Radheshyam Rai.

39. Camtakan, Z.; Erenturk, S.A.; Yusan, S.D.; Environ. Prog. Sustain. Energy, 2012, 31, 536.

40. Hornak, J.; Trnka, P.; Kadlec, P.; Michal, O.; Mentlík, V.; Šutta, P.; Csányi, G.; Tamus, Z.; Nanomaterials, 2018, 8, 381.

41. Bhattacharya, P.; Swain, S.; Giri, L.; Neogi, S.; J. Mater. Chem. B., 2019, 7, 4141. 
42. Bindhu, M.R.; Umadevi, M.; Kavin Micheal, M.; Arasu, M.V.; Abdullah Al-Dhabi, N.; Mater. Lett., 2016, 166, 19.

43. Essien, E.R.; Atasie, V.N.; Okeafor, A.O.; Nwude, D.O.; Int. Nano Lett., 2020, 10, 43.

44. Noori, A.J.; Kareem, F.A.; Heliyon, 2019, 5, e02568.

45. Suryavanshi, A.; Khanna, K.; Sindhu, K.R.; Bellare, J.; Srivastava, R.; Biomed. Mater., 2017, 12, 055011.

46. Tai, C.Y.; Tai, C. T.; Chang, M. H.; Liu, H.-S.; Ind. Eng. Chem. Res., 2007, 46, 5536.

47. Singh, R.P.; Application of Nanomaterials Towards Development of Nanobiosensors and Their Utility in Agriculture, Springer Publisher, New York, USA, 2017, Ch 14, pp293-303. In book "Nanotechnology: An Agricultural Paradigm" Editors: Prasad, Ram; Manoj, Kumar; Kumar, Vivek (Eds.).

48. Khot, L.R.; Sankaran, S.; Maja, J.M.; Ehsani, R.; Schuster, E.W.; Crop Prot., 2012, 35, 64.

49. Singh, R.P.; Utility of Nanomaterials in Food Safety, in: Food Saf. Hum. Heal., Elsevier, 2019, pp.285-318.

50. Ganapathi Rao, K.; Ashok, C.; Venkateswara Rao, K.; Shilpa Chakra, C.; Int. J. Sci. Res., 2014, 3, 43.

51. He, Y.; Ingudam, S.; Reed, S.; Gehring, A.; Strobaugh, T.P.; Irwin, P.; J. Nanobiotechnology, 2016, 14, 54.

52. Ogunyemi, S.O.; Zhang, F.; Abdallah, Y.; Zhang, M.; Wang, Y.; Sun, G.; Qiu, W.; Li, B.; Artif. Cells, Nanomedicine, Biotechnol., 2019, 47, 2230.

53. Cai, L.; Chen, J.; Liu, Z.; Wang, H.; Yang, H.; Ding, W.; Front. Microbiol., 2018, 9.

54. Abdallah, Y.; Ogunyemi, S.O.; Abdelazez, A.; Zhang, M.; Hong, X.; Ibrahim, E.; Hossain, A.; Fouad, H.; Li, B.; Chen, J.; Biomed Res. Int., 2019, 2019, 1.

55. Abdallah, E.S.H.; Mahmoud, M.M.; Abdel-Rahim, I.R.; J. Fish Dis., 2018, 41, 1719.

56. Huber, D.M.; Jones, J.B.; Plant Soil, 2013, 368, 73

57. Wang, W.N.; Tarafdar, J.C.; Biswas, P.; J. Nanoparticle Res., 2013, 15, 1417.

58. Chen, J.; Peng, H.; Wang, X.; Shao, F.; Yuan, Z.; Han, H.; Nanoscale, 2014, 6, 1879 .

59. Rao, W.; Zhan, Y.; Chen, S.; Xu, Z.; Huang, T.; Hong, X.; Zheng, Y.; Pan, X.; Guan, X.; J. Agric. Food Chem., 2018, 66, 3651.

60. Imada, K.; Sakai, S.; Kajihara, H.; Tanaka, S.; Ito, S.; Plant Pathol. 2016, 65, 551.

61. Radzig, M.A.; Nadtochenko, V.A.; Koksharova, O.A.; Kiwi, J.; Lipasova, V.A.; Khmel, I.A.; Colloids Surfaces B Biointerfaces., 2013, 102, 300.

62. Liang, C.; Sasaki, T.; Shimizu, Y.; Koshizaki, N.; Chem. Phys. Lett., 2004, 389, 58.

63. Camtakan, Z.; Erenturk, S.A.; Yusan, S.D.; Environ. Prog. Sustain. Energy, 2012, 31, 536

64. Park, J.Y.; Lee, Y.J.; Jun, K.W.; Baeg, J.O.; Yim, D.J.; J. Ind. Eng. Chem., 2006, 12, 882.

65. Štengl, V.; Bakardjieva, S.; Maříková, M.; Bezdička, P.; Šubrt, J.; Mater. Lett., 2003, 57, 3998.

66. Yu, J.C.; Xu, A.; Zhang, L.; Song, R.; Wu, L.; J. Phys. Chem. B., 2004, 108, 64

67. Jorfi, S.; Barzegar, G.; Ahmadi, M.; Darvishi Cheshmeh Soltani, R.; Alah Jafarzadeh Haghighifard, N.; Takdastan, A.; Saeedi, R.; Abtahi, M.; J. Environ. Manage., 2016, 177, 111.

68. Ng, B.J.H.; Zhou, J.; Giannis, A.; Chang, V.W.C.; Wang, J. Y.; J. Environ. Manage., 2014, 140, 60 .

69. Bagheri GH, A.; Sabbaghan, M.; Mirgani, Z.; Acta Part A Mol. Biomol. Spectrosc., 2015, 137, 1286.

70. Mohammadi, L.; Bazrafshan, E.; Noroozifar, M.; AnsariMoghaddam, A.; Barahuie, F.; Balarak, D.; Water Sci. Technol., 2017, 76, 3054.

71. Cai, Y.; Li, C.; Wu, D.; Wang, W.; Tan, F.; Wang, X.; Wong, P.K.; Qiao, X.; Chem. Eng. J., 2017, 312, 158.

72. Askari, P.; Faraji, A.; Khayatian, G.; Mohebbi, S.; J. Iran. Chem. Soc., 2017, 14, 613.

73. Khayatian, G.; Jodan, M.; Hassanpoor, S.; Mohebbi, S.; J. Iran. Chem. Soc., 2016, 13, 831.

74. Štengl, V.; Bakardjieva, S.; Maříková, M.; Šubrt, J.; Opluštil, F.; Olšanská, M.; Open Chem., 2004, 2.
75. Ali, S.; Farrukh, M.A.; Khaleeq-ur-Rahman, M.; Korean J. Chem. Eng., 2013, 30, 2100.

76. Lange, L.E.; Obendorf, S.K.; Arch. Environ. Contam. Toxicol., 2012, 62, 185.

77. Behnam, R.; Morshed, M.; Tavanai, H.; Ghiaci, M.; Bull. Environ. Contam. Toxicol., 2013, 91, 475.

78. Singh, R.P.; Pandey, A.C.; Anal. Methods, 2011, 3, 586.

79. Singh, R.P.; Kang, D.-Y.; Oh, B.-K.; Choi, J.-W.; Biotechnology and Bioprocess Eng., 2009, 14, 443.

80. Wang, L.; Electrochem. Commun., 2004, 6, 225.

81. Lu, L.; Zhang, L.; Zhang, X.; Wu, Z.; Huan, S.; Shen, G.; Yu, R.; Electroanalysis, 2010, 22, 471.

82. Dong, X.; Li, M.; Feng, N.; Sun, Y.; Yang, C.; Xu, Z.; RSC Adv., 2015, 5, 86485.

83. Nguyen, V.Q.; Lee, H.-D.; Jung, H.S.; Tai, W.P.; Lee, J.-S.; J. Nanosci. Nanotechnol., 2011, 11, 1333.

84. An, Y.; Zhang, K.; Wang, F.; Lin, L.; Guo, H.; Desalination, 2011 $281,30$.

85. Kailasa, S.K.; Wu, S.H.-F.; Microchim. Acta., 2013, 180, 405.

86. Ramanujam, K.; Sundrarajan, M.; J. Text. Inst., 2015, 106, 1147.

87. Singh, R.P.; Choi, J.-W.; Tiwari, A.; Pandey, A.C.; Utility and Potential Application of Nanomaterials in Medicine, in: Biomed. Mater. Diagnostic Devices, John Wiley \& Sons, Inc., Hoboken, NJ, USA, 2012, pp. 215-262.

88. Chalkidou, A.; Simeonidis, K.; Angelakeris, M.; Samaras, T.; Martinez-Boubeta, C.; Balcells, L.; Papazisis, K.; DendrinouSamara, C.; Kalogirou, O.; J. Magn. Magn. Mater., 2011, 323, 775.

89. Mahmoud, A.; Ezgi, Ö.; Merve, A.; Özhan, G.; Int. J. Toxicol., 2016, 35, 429.

90. Goyal, R.; Macri, L.K.; Kaplan, H.M.; Kohn, J.; J. Control. Release, 2016, 240, 77.

91. Castro, L.; Blázquez, M.L.; ángel Muñoz, J.; González, F.G.; Ballester, A.; Rev. Adv. Sci. Eng., 2014, 3, 199.

92. Wang, L.; Hu, C.; Shao, L.; Int. J. Nanomedicine, 2017, 12, 1227.

93. Jin, T.; He, Y.; J. Nanoparticle Res., 2011, 13, 6877.

94. Sundararajan, M.; Suresh, J.; Gandhi, R.R.; Dig. J. Nanomater. Biostructures, 2012, 7, 983.

95. Imani, M.M.; Safaei, M.; J. Nanotechnol., 2019, 2019, 1.

96. Maghsoodlou, S.; Afzali, A.; Concepts, Mod. Appl., 2015, 137.

97. Bertinetti, L.; Drouet, C.; Combes, C.; Rey, C.; Tampieri, A.; Coluccia, S.; Martra, G.; Langmuir., 2009, 25, 5647.

98. Martinez-Boubeta, C.; Balcells, L.; Cristòfol, R.; Sanfeliu, C.; Rodríguez, E.; Weissleder, R.; Lope-Piedrafita, S.; Simeonidis, K.; Angelakeris, M.; Sandiumenge, F.; Calleja, A.; Casas, L.; Monty, C.; Martínez, B.; Nanomedicine Nanotechnology, Biol. Med., 2010 , 6,362 .

99. He, Y.; Ingudam, S.; Reed, S.; Gehring, A.; Strobaugh, T.P.; Irwin, P.; J. Nanobiotechnology, 2016, 14, 54.

100. Rana, S.; Kalaichelvan, P.T.; Adv. Biotechnol., 2011, 11, 21.

101. Ram, P.; Vivek, K.; Kumar, S.P.; African J. Biotechnol., 2014, 13, 705.

102. Mazaheri, N.; Naghsh, N.; Karimi, A.; Salavati, H.; Iranian Journal of Biotechnology, 2019, 17(1).

103. Saleem, K.; Wani, W.A.; Haque, A.; Milhotra, A.; Ali, I.; Nanodrugs: Magic Bullets in Cancer Chemotherapy, in: K. Saleem, W. A. Wani, A. Haque, A. Milhotra, I. Ali (Eds.), Top. Anti-Cancer Res., Bentham Science Publishers, 2013, pp. 437-494.

104. I. Ali, Rahis-Uddin, K.; Salim, M.; Rather, A.; Wani, W. A.; Haque, A.; Curr. Cancer Drug Targets, 2011, 11, 135.

105. Ali, I.; Curr. Cancer Drug Targets, 2011, 11, 130

106. Di, D.R.; He, Z.Z.; Sun, Z.Q.; Liu, J.; Nanomedicine Nanotechnology, Biol. Med., 2012, 8, 1233.

107. Koper, O.B.; Klabunde, J.S.; Marchin, G.L.; Klabunde, K.J.; Stoimenov, P.; Bohra, L.; Curr. Microbiol., 2002, 44, 49.

108. Imani, M.M.; Safaei, M.; J. Nanotechnol., 2019, $2019,1$.

109. Jin, T.; He, Y.; J. Nanoparticle Res., 2011, 13, 6877.

110. Bhattacharya, P.; Swain, S.; Giri, L.; Neogi, S.; J. Mater. Chem. B., 2019, 7, 4141.

111. Hayat, S.; Muzammil, S.; Rasool, M.H.; Nisar, Z.; Hussain, S.Z.; Sabri, A.N.; Jamil, S.; Microbiol. Immunol., 2018, 62, 211. 
Advanced

Materials Letters

www.vbripress.com/aml

www.iaamonline.com

112. De Silva, R.T.; Mantilaka, M.M.M.G.P.G.; Goh, K.L.; Ratnayake, S.P.; Amaratunga, G.A.J.; De Silva, K.M.N.; Int. J. Biomater., 2017, 2017, 1 .

113. Noori, A.J.; Kareem, F.A.; Heliyon., 2019, 5, e02568.

114. Khalid, A.; Norello, R.; Abraham, A. N.; Tetienne, J.-P.; Karle, T. J.; Lui, E. W. C.; Xia, K.; Tran, P. A.; O'Connor, A. J.; Mann, B. G.; de Boer, R.; He, Y.; Man Ching Ng, A.; Djurisic, A. B.; Shukla, R.; Tomljenovic-Hanic, S.; Nanomaterials, 2019, 9, 1360.

115. Singh, R.P.; J. Bioanal. Biomed., 2016, 8.

116. Solanki, P.R.; Kaushik, A.; Agrawal, V. V.; Malhotra, B.D.; NPG Asia Mater., 2011, 3, 17.

117. Singh, K.R.B.; Fernandes, M.; Sarkar, T.; Sridevi, P.; Infect. Non Infect. Dis., 2019, $4,1$.

118. Singh, K.R.B.; Sridevi, P.; Singh, R.P.; Potential Applications of Peptide Nucleic Acid (PNA) in biomedical domain, 2019.

119. Singh, R.P.; Oh, B.-K.; Choi, J.-W.; Bioelectrochemistry, 2010, 79, 153.

120. Patel, M.; Agrawal, V.V.; Malhotra, B.D.; Ansari, S.G.; Mater. Focus, 2014, 3, 1.

121. Lei, Z.Q.; Li, L.; Li, G.J.; Leung, C.W.; Shi, J.; Wong, C.M.; Lo, K.C.; Chan, W.K.; Mak, C.S.K.; Chan, S.B.; Chan, N.M.M.; Leung, C.H.; Lai, P.T.; Pong, P.W.T.; J. Appl. Phys., 2012, 111, $07 \mathrm{E} 505$.

122. Li, M.; Guo, W.; Li, H.; Dai, W.; Yang, B.; Sensors Actuators B Chem., 2014, 204, 629.

123. Umar, A.; Rahman, M.M.; Hahn, Y.-B.; Electrochem. Commun., 2009, 11, 1353.

124. Shah, V.B; Henson, W.R.; Chadha, T.S.; Lakin, G.; Liu, H.; Blankenship, R.E.; Biswas, P.; Langmuir, 2015, 31, 1675.

125. Singh, R.P.; Int. J. Electrochem., 2011, 2011, 1.

126. Singh, R.P.; Oh, B.K.; Koo, K.K.; Jyoung, J.Y.; Jeong, S.; Choi, J.W.; Biochip J., 2009, 2, 223.

C) IAAM - VBRI Press

Adv. Mater. Lett. 2020, 11(8), 20081543

[10 of 10] 